\title{
Utilizing Social Media Data Analytics to Enhance Banking Services
}

\author{
Mohamed Abd El-Hamid Farag Ahmed Askar¹, Amal Elsayed Aboutabl², Amr Galal ${ }^{3}$ \\ ${ }^{1}$ Business Information Systems, Faculty of Commerce and Business Administration, Helwan University, Cairo, Egypt \\ ${ }^{2}$ Faculty of Computers and Artificial Intelligence, Helwan University, Cairo, Egypt \\ ${ }^{3}$ Faculty of Commerce and Business Administration, Helwan University, Cairo, Egypt \\ Email: mohamed.abdelhamid021@commerce.helwan.edu.eg, amal.aboutabl@fci.helwan.edu.eg
}

How to cite this paper: Askar, M.A.E.H.F.A., Aboutabl, A.E. and Galal, A. (2022) Utilizing Social Media Data Analytics to Enhance Banking Services. Intelligent Information Management, 14, 1-14. https://doi.org/10.4236/iim.2022.141001

Received: December 5, 2021

Accepted: January 18, 2022

Published: January 21, 2022

Copyright (c) 2022 by author(s) and Scientific Research Publishing Inc. This work is licensed under the Creative Commons Attribution International License (CC BY 4.0).

http://creativecommons.org/licenses/by/4.0/

\section{(c) (i) Open Access}

\begin{abstract}
The two most important challenges facing banks today are attracting new customers and retaining their existing ones. Research shows that 30 percent of banks cited customer loyalty as their biggest challenges. Thus, given that customer loyalty is completely connected to customer delight. The challenging question is: How do banks achieve customer delight by making every interaction a pleasant experience? In our viewpoint "The key is to stop treating customers as segments and personalize all customer interactions and services which can be achieved by using the latest technological advancements in Big Data Analytics, Artificial Intelligence (AI) and Machine Learning". With the rapidly increasing usage of social media like Facebook, Twitter, LinkedIn, and Instagram, business organizations are now moving towards adapting this technology to drive business advantages. This research will explore the power of social media and how it can be used by banks to provide an edge over their competitors by providing improved products and services to their customers thereby making their experience easy and responsive. It also proposes a framework for social media analytics and its important components to address all the technical and business aspects of the retail and online banking, however, what customer expects from this medium and what banks offer to them needs to be widely studied and understood.
\end{abstract}

\section{Keywords}

Natural Language Processing (NLP), Sentiment Analysis, Social Banking, Information Retrieval (IR), Social Media Analytics

\section{Introduction}

Social media is the fastest growing technology since its inception. It is a medium 
which allows interaction. Web 2.0 is an example of social media. Other widely used social media are the Facebook, Twitter, Blogs, Wikis, LinkedIn, and Instagram. The concept of social media is top of the agenda for many business executives today. With approximately two billion people using social media around the world banks must seriously consider how to engage with customers on social channels. Social media is dramatically impacting the banking industry, as most banks have established a presence on various social sites through Twitter, Facebook, Google+, LinkedIn, etc. Banks can be benefited by social media in a way that makes them think fresh and enhance their services to attract customers [1].

Banks need to understand the reach and prospective of social banking and financial social networks. Then they can have a better chance of adapting themselves to the demands of the customers. Once banks start involving themselves with customers they get access to:

1) A dynamic network which keeps on growing.

2) The ability to record, monitor, and analyze social interactions, personal preferences and behavior of customers.

3) Instant feedback and reaction-instant communication from any device.

\section{Overview}

In this research we review two relevant areas of the literature, and identify a gap in knowledge. First, we discuss social media and its use by business. Second, we discuss social media analytics and its impact on business.

\section{$>$ Social Media and its use in Business}

Social media enables users to generate content by sharing their knowledge, opinions and experiences on a wide variety of issues. A recent survey indicates that 4 out of 5 internet users actively use various types of social media. Clearly, social media applications generate vast amounts of data that are potentially of great use to business. Social media has changed the way customers engage with businesses, brands, products and services. They have become more suspicious about traditional advertisements and start to rely more on information on social media to support their decision-making. Experiences, opinions and sentiments towards products and services may be either positive or negative and may influence attitudes, perceptions and buying decisions of consumers. Social media provides businesses with many opportunities. It provides a new and powerful marketing channel that is low cost and can be harnessed to increase customer awareness toward businesses and their associated brands, products and services, and improve overall business efficiency. It also enables businesses to improve their customer relationships through better engagement on a real time basis. For example, National Australia Bank's "Break Up With Your Bank" campaign on Twitter and Youtube resulted in increases to its Twitter followers and Facebook fans, reflecting more awareness of its business, and increases in credit card and mortgage applications, mortgage market share and queries from competitors' customers [2]. 


\section{Social Media Analytics and Business Impact}

The use and importance of social media by business is expected to grow in the future, in particular the use of analytical capabilities to analyze and interpret vast amounts of online information to gain costumer and business insight. Social media analytics has been widely used in e-commerce, for customer and market intelligence, in supply chain and product development, in e-government and politics, to achieve influence and improved customer relationships, brand awareness and marketing, scale and speed, lower costs and flexibility in operations. However unlike the structured data used in traditional business analytics systems social media data is characterized by heterogeneous and unstructured formats and comprises human natural language that is heavily context dependent. Business analytics techniques used include information retrieval and text mining, natural language processing, machine learning, data mining, and social network analysis. Combining these technologies with associated organizational processes and routines, and people with relevant skills and knowledge creates to social media analytics capabilities. These include sentiment analysis, involving the analysis and interpretation of data to determine opinions and sentiments towards products, brands and marketing campaigns, and social network analysis, involving the analysis of relationships between social media users and communities, and the identification of key social influencers. A number of companies, including KIA motors and The Royal Bank of Canada, have achieved benefits from social media analytics including product innovation, customer service improvement, and identification of new business opportunities [3].

\section{Research Problem}

Data cleansing-cleaning unstructured textual data (e.g., normalizing text), especially high-frequency streamed real-time data like social media, still presents numerous problems and research challenges.

Data analytics-sophisticated analysis of social media data for opinion mining (e.g., sentiment analysis) stillraises a myriad of challenges due to foreign languages, foreign words, slang, spelling errors and the naturalevolving of language.

\section{$>$ Challenges of Social Data}

Adopting social media and analyzing social media data more effectively alsoinvolves a number of challenges.

Unstructured data: Social media data is not like other forms of data, for example, survey data. Social data is mostly unstructured. It is impossible to apply any numeric analysis directly. Some of the newer Artificial Intelligence-based methods, such as Natural Language Processing could help with the analysis; however these are still in early stages of development. In order to getbetter understanding of banking conversations, a proper text analytics method is needed.

Noise in social media data: Noise here refers to the undesired data present in a dataset. Noisy data is "meaningless data" which is often used as a synonym for any data that cannot be understood and interpreted correctly. The inherently 
linked nature of social data further complicates the analysis task and requires analysts to approach noise-removal differently than they would with attributevalue data. This can be a time-consuming task.

Data representation: Social media is only part of the overall conversation. More than that, the social data we can tap into on sites such as Facebook and Twitter may merely constitute a fraction of what is being said about your company or products in specialist and word-of-mouth forums, blogs and elsewhere online.

This below Table 1 summarizes Social media analysis key challenges:

\section{Social Media Measurement Challenges}

How to Calculate Social Media Metrics:

Our challenge is to develop the metrics that best describe and measure value for banking business.

\section{$>$ Lack of control over content}

In social media, the ability to edit the content and share it across the networks is in the hands of the user. Consequently, banks may face the risk of purposeful attacks aimed at damaging the bank's image. Companies should therefore always

Table 1. Social media key challenges [4].

\begin{tabular}{|c|c|}
\hline Challenge & Description \\
\hline Inconsistent Dataset & $\begin{array}{l}\text { - Different tools have different filtering capabilities } \\
\text { - Solutions can only draw from public Facebook posts to protect privacy. } \\
\text { - Different tools have different access to the Twitter "firehose". } \\
\text { - Crawlers and spam filters also affect dataset results. }\end{array}$ \\
\hline New Behaviors & $\begin{array}{l}\text { - Social media creates new behaviors that must be interpreted, and the value must be } \\
\text { understood. Examples: } \\
\text { o A "Like" on Facebook. } \\
\text { o A re-tweet on Twitter } \\
\text { o A check-in on Foursquare } \\
\text { - Answers vary based on industry and business objective. }\end{array}$ \\
\hline Disparate Sources & $\begin{array}{l}\text { - Most brand conversations occur off the main website, outside the reach of } \\
\text { traditional web analytics providers } \\
\text { - New apps generate data from an ever-increasing array of sources, } \\
\text { each with different characteristics. } \\
\text { - Social analytics solutions are still new; few case studies from which to learn. }\end{array}$ \\
\hline Language Limitations & $\begin{array}{l}\text { - Industry terms } \\
\text { - Slang and abbreviations: LOL, OMG, TTYL, ROFL } \\
\text { - Irony and sarcasm } \\
\text { - Emoticons }:- \\
\text { - Uneven support for global languages }\end{array}$ \\
\hline $\begin{array}{l}\text { Different Analytical } \\
\text { Approaches by Vendors }\end{array}$ & $\begin{array}{l}\text { Differing approaches to data collection affect results: } \\
\text { - Keyword-based is the simplest and least expensive, but least accurate. } \\
\text { - Natural language processing and algorithmic approaches are more } \\
\text { sophisticated and expensive. }\end{array}$ \\
\hline
\end{tabular}


be careful when they give the power to their customers and the wider public. Both the tracking and detection of potential issues is essential, so that control is not totally lost and immediate action can be taken. In other cases, banks are likely to view these instances as purposeful attacks; where customers use online forums to express their dissatisfaction with the bank's services or its policies

\section{Lack of safety regulations and standards}

Most banks express their concerns over the lack of safety regulations and standards in social media. The banking industry is highly sensitive and it faces additional security requirements not don't exist in other industries. The more conservative banks state their major concerns as follows:

- Information privacy

- Lack of control over data

- Negative impact on corporate image

However, this does not make social media usage impossible for banks. It simply means that these initiatives require careful planning, more attention to detail and putting proper controls in place to manage social media data and content.

\subsection{Research Questions}

Nowadays there are million active internet users worldwide using social media application to share ideas and opinions on products, services and brands. So social media not only has a massive amount of content on that present opinions on products and services, but also this content has a large readership compared with any other traditional media like newspapers, magazines, TV, and radio. Hence a large number of consumers reading opinions about products and services on posts, tweets and blogs are more likely to adopt these opinions as opposed to being influenced by traditional advertising [5].

This rise of the social media has empowered the average consumer with the ability to influence the public perception and profitability of business organizations. As a result, organizations need to be mindful of what people in general (and potential customers in particular) are saying in social media, how the expressed customers' opinions could impact their business, and how to extract (and drive) business insight and value from these posts, tweets and blogs. This has given rise to the emerging discipline of Social Media Analytics, which draws from Social Network Analysis, Machine Learning, Data Mining, Information Retrieval (IR), and Natural Language Processing (NLP). The automated analysis of social media raises several interesting questions from a marketing perspective:

1) Given the enormous amount of data collected from social media, how can we identify the subset of posts, blogs and forums that are discussing not only a specific product, but higher level concepts that are in some way relevant to this product?

2) Having identified this subset of relevant data, how do we identify the most authoritative or influential users in this space? 
3) How do we detect and characterize specific sentiment expressed about an entity (e.g. product) mentioned in a post, tweet, blog or forum?

4) How do we filter novel emerging topics of discussion from the constant chatter in social media network?

In this research we discuss techniques from the related sub-disciplines of Social Media Analytics that can be adapted to address the above problems. We also point out some of the limitations in these approaches, and discuss unexplored directions that we believe are required to advance the state-of-the-art in this rapidly evolving area.

\subsection{Theoretical Foundation}

In this study our main purpose of research was to critically go over the theoretical and empirical review of literature related to the topic of social media analytics in banking domain and other related concepts that support the research ideas. Most of the research done concentrates on how social media analytics and intelligence affect bank' performance.

From all reviewed literature we found that in the last couple of years, different kind of social media networking services have emerged and currently there are innumerable social media channels that connect people to each other. The most popular social network sites that are widely used are; Facebook, Twitter, YouTube and LinkedIn which are now the most common channels companies use in their online marketing for creating brand awareness or just engaging with the customers. Social media includes web and mobile-based technology that induce users to interrelate with each other by creating and sharing user-generated content. The next picture (Figure 1) shows the main social media types with their description by considering the present research:

Social networking is the use of Internet-based social media sites to stay connected with friends, family, colleagues, customers, or clients. Social networking can have a social purpose, a business purpose, or both, through sites like Facebook, Twitter, LinkedIn, and Instagram.

Blogging is an online journal where people can share their experiences or share information with other readers on any topic. Blogs allow the owners to post a reversed chronological order; new posts first appear at the top while the oldest posts are at the bottom.

Microblogging is a combination of instant messaging and content production. With a microblog, you share short messages with an online audience to improve engagement. Social channels like Twitter, Instagram, Facebook and Pinterest offer popular platforms for microblogging.

Online rating is review of a product or service made by a consumer who has experienced a service or purchased a product.

Social bookmarking is an online service which allows a way for users to search, manage, organize, and store useful web content they'd like to revisit and share with others. 


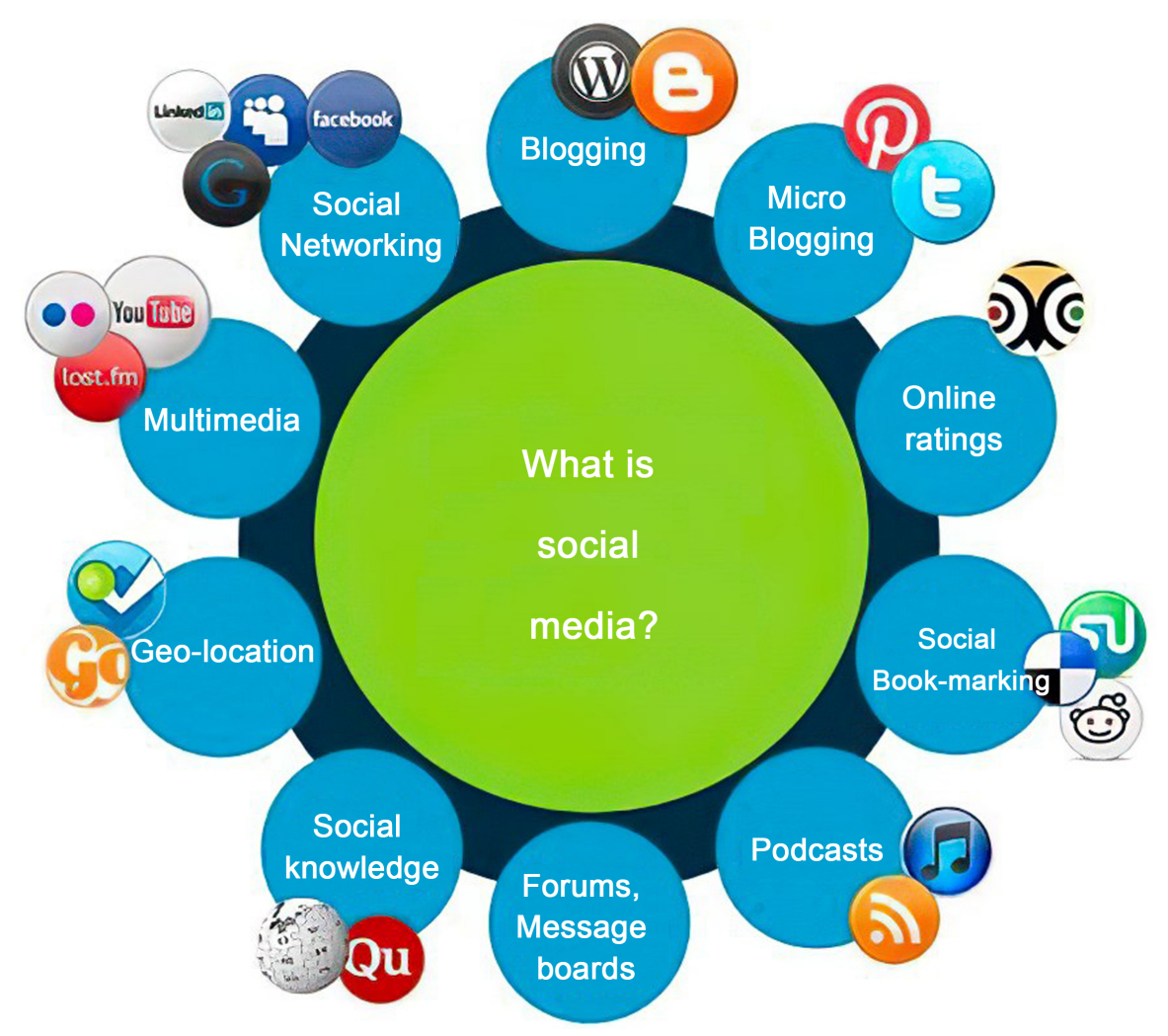

Figure 1. Social media types [6].

A podcast is a recording of audio discussion on a specific topic, like business or travel that can be listened to. Podcasts can be an excellent way to develop an intimate connection with listeners and potential customers.

An Internet forum, or message board is an online discussion site where people can hold conversations in the form of posted messages. They differ from chat rooms in that messages are often longer than one line of text, and are at least temporarily archived.

Social knowledge is the collective knowledge produced through relationships and connections within a particular group. It can be the collective knowledge base of small groups, like a family, or it can be a massive and constantly evolving body of knowledge, like Facebook because they are produced through ongoing collaboration and contributions of information within a collective.

Geolocation refers to the use of location technologies such as GPS or IP addresses to identify and track the whereabouts of connected electronic devices. Geolocation data is an essential parameter for creating an effective social advertising strategy. Location not only helps you figure out where your customer is but careful analysis of their visits and local searches can help you create relevant, personalized and targeted ads.

A multimedia social network is a network in which a group of users share and exchange multimedia content, as well as other resources. Multimedia content is an essential part of today's content marketing strategies. It can help boost 
your conversion rates and change how users interact with your social media accounts.

Many researchers studied the impact and the benefits of social media throw various variables on organizational performance, brand loyalty, competitive advantage and consumer buying behavior, such as: Parveen [6] stated in his study results that social media usage has a very strong positive impact on organizations' performance, in terms of cost reduction, , improved customer relations, and enhanced information accessibility. Also Moen [7] studied the use of social media and its impact on organizations which was found that it has a positive impact on firm's satisfaction. Kimani [8] stated in his study results that social media marketing has a lot of value to people because it allows employees to connect to the clients, especially the ones in different geographic zones, social media allows firms to engage in timely and direct end-consumer contact at fairly low cost and higher levels of efficiency than can be achieved with more traditional communication tools. Furthermore, Apigian [9] in a research to study the relationship between business internet use and social media marketing which he found an increase of revenue expansion, relationship enhancement, cost reduction, and time reduction. Durga [10] Stated that social media is not just about leaving trivial comments or liking pictures on Facebook, it has huge implications for organizations for their internal use such as knowledge management as well as for external uses such as sales and marketing. Also Ferrer [11] investigated the impact of social media technologies and found that it positively impacts the social capital of an organization and subsequently its performance. Furthermore, the use of social media helps organizations to promote and increase customer relations and customer services effectiveness.

A study done by Bhanot Sandeep [12] develops a test on the impact of social media usage on two dependent variables of performance (reach out more customer and increase in sales). The researcher concludes that Majority of the companies are using a combination of traditional and social media to reach out to their customers. It has been seen that use of social media helped companies to reach out to more customers and to satisfy their needs better in addition to creating a real time communication with their customers, and also the researcher indicates that Companies can use the social media better by making their message clear, avoiding chaos and ensuring that their online image matches with their brand image. On the other hand; Rajiv [13] said that as the popularity of social media is growing and there is no turning back it seems social media will overtake to other functional areas of marketing to a large extent. Social media is trying to fill the gap between marketers and consumers through continual dialogue, timely communication, creating competitive advantage, building trust and interacting with right audience in right way and time, as fast as possible.

Thus, based on these previous studies, we will attempt to investigate contribution of social media analytics on decision making process, marketing plans, customer real time communication, repeat exposure, and competitive advantage for 
banking industry in Egypt. This research will consider Social media analytics as independent variables, while organizational performance (real time communication, repeat exposure and competitive advantage) as dependent variables. More specifically, the purpose of the current research is to investigate the impact of social media analytics usage on banking industry performance in Egypt.

\section{Research Objectives}

The research questions are answered using a research approach comprising two steps: development of an initial framework followed by an analysis of vendor success stories to refine and enhance the framework. The initial framework will be developed from an extensive analysis of relevant literature. Relevant papers were identified from key information systems journals and conferences based on the terms "social media", "social networks", "web analytics", "business analytics" and "social media analytics". Much of the work in social media analytics is found in conferences and practitioner white papers as the phenomenon is so recent.

The second step is an analysis of vendor success stories to refine and enhance the proposed framework. The stories were sourced from vendor web sites and comprised "white paper" type reports of 3 - 4 pages in length that discussed success stories related to the use of social media analytics in achieving business benefits.

\section{Importance of Research}

As banks tend to merge new ways in their business, there should be a gradual shift in the way banks connect with their customers. This shift in the informational and transactional touch points, together with increasing social media usage can offer vast opportunities to the banks to better understand customer needs, thereby improving the products and services. Some of the vast opportunities banks can reap from social media usage to enhance the customer experience are:

\section{Customized Marketing}

Banks can use social media to run targeted marketing campaigns, thereby reducing the overall cost of marketing. For example, if a customer updates his status on social media about his dining into local restaurants, banks can take this information to offer cash backs offers, loyalty points etc.

\section{Customer Insight}

Banks can use customer data available on social media to again insights into his activities. For example, say a customer may use social media to inform his friends about his wedding. Bank can use this information and suggest suitable products and services.

\section{$>$ Improved Product Development}

As more and more customers are using social media daily, banks can exploit this to gather customer feedback about their products and services. It can also help banks to tailor products to cater the varying needs of the customers. 


\section{Increase Sales}

Based on customer behavior on social media, such as posts and likes, banks can use analytics to generate leads from this data, which can be used to perform next best analysis and develop next best actions.

\section{Improved Customer Service}

Banks can use social media responses of the customers to know about their experience with the bank's products and services. Thereby, banks can solve customer's problem in time and make the customer feel satisfied by providing quick response to their complaints.

\section{$>$ Increase Brand Value}

Banks can increase their brand value by reaching out to broad range of customers through social media. A positive feedback about a product or service by the bank's customer can be read and shared by others on social media, thereby exposing the strengths to wider range of customers [14].

\section{A Proposed Framework}

In the recent times, there has been an increased focus on getting a $360^{\circ}$ view of the customers. In order to get this complete picture of customers, banks should be able to address the "what" and the "why" with regards to the customer's banking transactions. We believe that by coupling the customer's banking transactions with the social media activities can help the banks in getting a better $360^{\circ}$ understanding regarding their customers.

Currently, by using the numerous transactional data, which the banks already have, we can addressed the "what"-what transactions customers had made in the past? However, the banks are not in a position to address the "why"-why are customers making these transactions? In essence, social media can help the banks in understanding the context (why) behind the consumer transactions.

The proposed framework for social media analytics in banking domain relies on three major aspects; Listen, Analyze and provide Insight as illustrated in Figure 2. Banks can listen (or monitor) to customer activities happening on their social media pages. By listening to these conversations, banks are collecting valuable social data of the customers. In the next step, banks can analyze or process this big (social) data, couple this social big data with the transactional data and get the insight into the customer's behaviors and understand the context behind these transactions.

In order to process and analyze the huge volume of data, the analytical model relies on Rule Engine. Rule Engine is the core of the model and it plays an important role in each of the tasks performed by it; from Case Management Framework to Transactional Framework. Rule Engine interprets the incoming data from social media channels and automatically identifies the nature of this datacustomer queries, sales leads or transactions. Based on these actions, appropriate actions are triggered by the Rule Engine. For instance, if the incoming data is identified as a customer query, then this data is automatically routed to the 


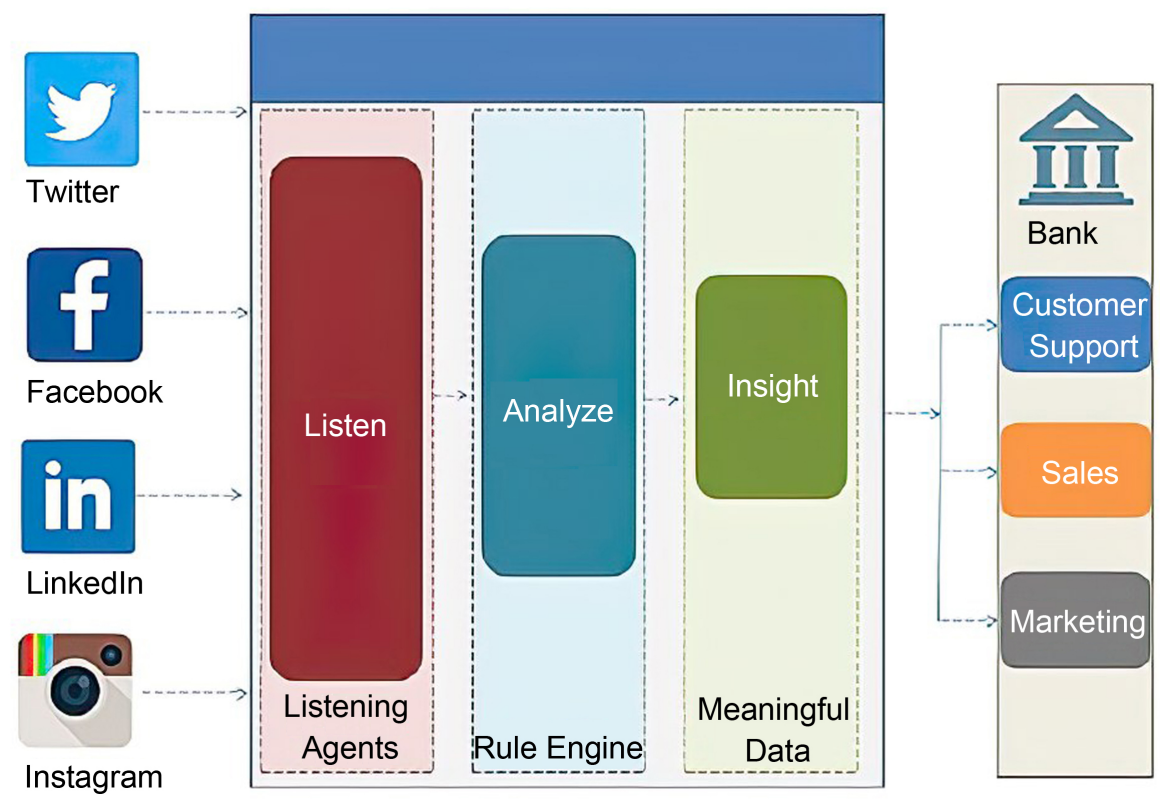

Figure 2. Framework model for social media analytics [11].

corresponding department which addresses the customer queries.

Framework model can also be used effectively to identify events on social media such as marriage, divorce, graduation, change of location, childbirth, retirement and more. Every important event in a customer's life triggers multiple changes in financial priorities and spending patterns. It has been proven that life's events have a positive correlation to the financial decisions a person takes. Some banks currently store customer-provided information and use it to offer suitable services and products. One example would be a customer adding a new family member to an insurance policy, which the bank can then use to offer a baby savings scheme.

Our proposed framework model will effectively decipher upcoming events using text analytics and sentiment analytics, based on social media content published by the user on Twitter or Facebook... Knowing events in advance can help banks target customers and prospects with personalized offers and services that are most suitable to them as per Figure 3:

External events such as a customer's web browsing patterns, number of visits to a particular site, or enquiries on a social networking site can act as identifiers for an upcoming events. Such examples could include:

- A web search for a product or service

- Visits to a car showroom

- Enquiries on social media for properties/home loans

- Frequent visits to travel sites

With the advent of online banking, massive amounts of data sourced from search engines and social feeds can be used for understanding the customers' intent and in engaging the customer in more meaningful ways with specific products/service offerings and recommends a personalized product offer when they 


\section{Fresh graduate}

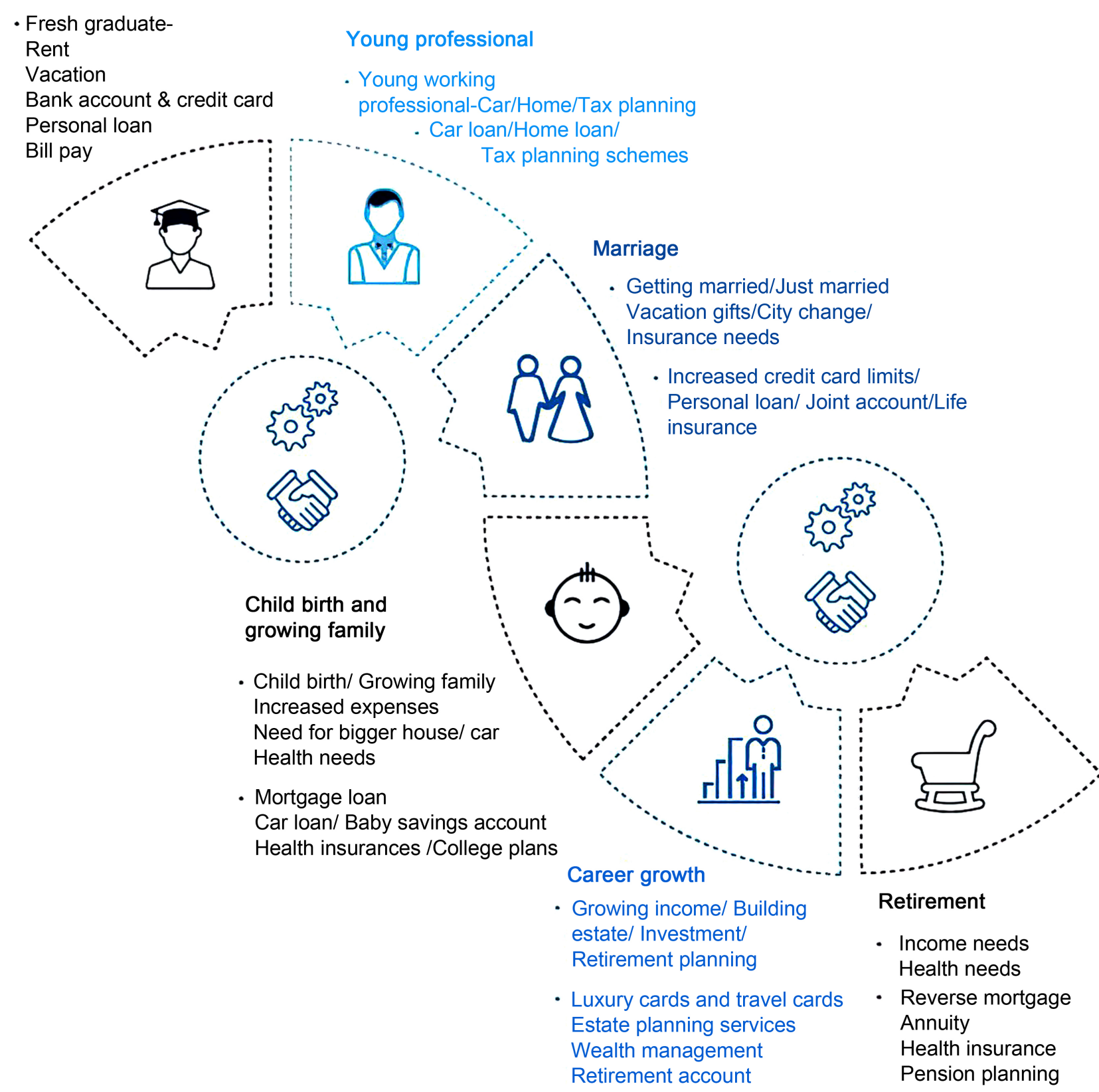

Figure 3. Social media users' events classification [14].

visit the bank's website [15].

\section{Research Scope and Limitation}

In this study, we will explore the business impact of social media analytics and will develop a framework that will lead to real business value when adopted. There are a number of implications for research and practice. For researchers, the framework is soundly based in organizational motivation and theory. There is no doubt that social media is embedding itself within the business and social 
activities of people. The evolution of Web 2.0 and social media technology has led to creation of vast amounts of information which may be analyzed and interpreted to gain customer and business insights. The proposed framework provides researchers with a lens for understanding and explaining the business impact of social media analytics. For practitioners, the framework provides a systematic means of planning and managing social media analytics projects. It provides a catalogue of typical motivations, social media analytics capabilities and benefits, and can guide investment decisions. Our research is limited by the use of vendor success stories. Although we argue that this is appropriate for the initial development of the framework, further research will require detailed case studies and surveys to further evaluate and refine the framework.

\section{Conclusion}

In the years to come, social media will become a widely accepted part of retail banking. Banks must emphasize on their understanding of social media in order to better deploy it to the fullest advantage. However, there is still a gap between how customers prefer to use social media in the banking and the services they are currently being provided by the banks. As banks move up for social media strategies, they should try to gain more intelligence about specific expectations the customer have from this medium.

\section{Conflicts of Interest}

The authors declare no conflicts of interest regarding the publication of this paper.

\section{References}

[1] Shilpa, H. (2018) Impact of Social Media Marketing on Performance of Micro and Small Businesses. D.Y. Patil University, Navi Mumbai.

[2] Nwokah, N. and Irimagha, B. (2017) E-Marketing Orientation and Social Media Implementation in the Banking Industry in Nigeria. iBusiness, 9, 111-133.

https://doi.org/10.4236/ib.2017.94009

[3] Asur, S. and Huberman, B.A. (2010) Predicting the Future with Social Media. 2010 IEEE/ WIC/ ACM International Conference on Web Intelligence and Intelligent Agent Technology, Toronto, 31 August-3 September 2010, 492-499. https://doi.org/10.1109/WI-IAT.2010.63

[4] Wickham, H. (2018) Ggplot2: Elegant Graphics for Data Analysis. 2nd Edition, Springer-Verlag, New York.

[5] Icha, O. and Agwu, M.E. (2015) Effectiveness of Social Media Marketing on Organization Performance. Journal of Internet Banking and Commerce, 21, Article No. 6.

[6] Parveen, F., Jaafar, N. I. and Ainin, S. (2018) Social Media Usage among Businesses: A Website Content Analysis. Asian Journal of Information Technology, 12, 342-348.

[7] Moen, Ø.M., Koed Madsen, T. and Aspelund, A. (2008) The Importance of the Internet in International Business-to-Business Markets. International Marketing Review, 25, 487-503. https://doi.org/10.1108/02651330810904053 
[8] Kimani, E. (2017) Role of Social Media Marketing on Organisational Performance in Kenya. IOSR Journal of Business and Management, 17, 101-105.

[9] Apigian, C.H., Nathan, R., Ragu-Nathan, T.S. and Kunnathur, A. (2015) Internet Technology: The Strategic Imperative. Journal of Electronic Commerce Research, 6, 123-145.

[10] Singla, M.L. and Durga, A. (2018) How Social Media Gives You Competitive Advantage. Indian Journal of Science and Technology, 8, 90-95. https://doi.org/10.17485/ijst/2015/v8iS4/60363

[11] Ferrer, E.B., González-Rivera, J., Maldonado-Pérez, M., Martínez-Maurosa, M. and Soto-Montes, E. (2019) Enriching Social Capital and Improving Organizational Performance in the Age of Social Networking. International Journal of Information, Business and Management, 13, 390-393.

[12] Bhanot, S. (2017) A Study on Impact of Social Media on Company Performance. College of Management Studies, Navi Mumbai.

[13] Rajiv, K. (2018) Impact of Social Media Marketing. International Journal of Computational Engineering \& Management, 15, 1-5.

[14] Okiro, K. and Ndungu, J. (2019) The Impact of Mobile and Internet Banking on Performance of Financial Institutions in Kenya. European Scientific Journal, 9, 146161. https://doi.org/10.19044/esj.2013.v9n13p\%p

[15] Ubiparipović, B. and Đurković, E. (2019) Application of Business Intelligence in the Banking Industry. Management Information Systems, 6, 23-30. 